\title{
Assessment of radiation exposure of Head and Neck during panoramic radiography in different age groups
}

\author{
Ehsan Moudi ${ }^{1}$, Sina Haghanifar ${ }^{1}$, Hoora Hadian ${ }^{2, *}$, Ali Shabestani Monfared ${ }^{3}$, \\ Gholamreza Deilam ${ }^{4}$, Nika Bahemmat ${ }^{5}$ \\ ${ }^{1}$ Department of Oral and Maxillofacial Radiology, Babol University of Medical Sciences, Babol, Iran \\ ${ }^{2}$ Post Graduate Student of Oral and Maxillofacial Radiology, Shahid Beheshti University of Medical Sciences, Tehran, Iran \\ ${ }^{3}$ Department of Biochemistry and Biophysics, Babol University of Medical Science \\ ${ }^{4}$ Private Dentist, Babol, Iran \\ ${ }^{5}$ Post Graduate Student of Oral and Maxillofacial Radiology, Shahid Beheshti University of Medical Sciences, Tehran, Iran
}

\section{Email address:}

h.haadian@yahoo.com (H. Hadian)

\section{To cite this article:}

Ehsan Moudi, Sina Haghanifar, Hoora Hadian, Ali Shabestani Monfared, Gholamreza Deilam, Nika Bahemmat. Assessment of Radiation Exposure of Head and Neck during Panoramic Radiography in Different Age Groups. Science Journal of Clinical Medicine. Vol. 3, No. 1, 2014, pp. 10-14. doi: 10.11648/j.sjcm.20140301.13

\begin{abstract}
Background and aim: Panoramic imaging is one of the most commonly used imaging techniques in dentistry. Being able to accurately assess the radiation dose patients receive during procedures is a crucial step in the management of dose. The main objective of this study was to evaluate the head and neck skin absorbed dose during panoramic radiography in different age groups with panoramic machine of Oral and Maxillofacial Radiology section of Babol school of dentistry. Materials and methods: 273 thermoluminescent dosemeters (TLDs) (100 LiF: Mg, Ti , harshaw, USA) were used.90 samples were selected from the patients who referred to the Oral and Maxillofacial Radiology section of Babol school of dentistry for panoramic radiography. .Samples divided in 3 age group: 4 - 10 years, $10 \_40$ years and above 40 years . TLDs were calibrated in dosimetry laboratory, National Radiation Protection Department. Thermoluminescent signal was read out with a Harshaw 4500 (Harshaw, Bicron USA) reader. Mean and standard deviation was determined by SPSS 10 software and ANOVA statistic analysis. Results: Mean \pm SD of skin absorbed dose of head and neck for 90 patients was $0.47 \pm 0.09 \mathrm{mGy}$. Conclusions: Since Diagnostic Reference level (DRL) of panoramic imaging is unknown in Iran, there is no possibility to compare the current results with DRL. However, This study conclude that decrease of radiation dose seems to be achievable with lower exposure condition with the panoramic unit.
\end{abstract}

Keywords: Radiography, Panoramic, Thermoluminescent Dosimetry, Thyroid Gland, Parotid Gland

\section{Introduction}

Medical exposures are the most important source of public exposure to man-made radiation. Nowadays the lesions detection and disease diagnosis are based on clinical and paraclinic findings. In the past decades, $x$-rays have been used widely in dentistry(1). Dental radiology is being extensively used especially after the consolidation of the dental implant technique(2).Therefore radiographic findings play an important role. Entrance surface dose(ESD), (named skin absorbed dose in current article), and dose-area product (DAP) are the most important parameters measured in diagnostic Radiology (3).Due to increasing radiological examinations, patient protection against X-rays is important. Therefore, all national and international forums have specific recommendations to further protection of patients. Being able to accurately assess the radiation dose patients receive during procedures is a crucial step in the management of dose $(4,5)$. Since the introduction of the term "diagnostic reference Level (DRL)" by ICRP in 1996 (ICRP,1996), there have been continuing worldwide efforts to develop and implement DRLs in diagnostic radiology as well as nuclear medicine(6),(7).ICRP in its 1996 publication recommends that to set DRLs(7). While no DRLs are proposed for panoramic radiographies by International Atomic Energy Agency(6), Selection of a DRL using a percentile point on the observed distribution of dose for patients, should be 
specific to a country or region (ICRP 2002)(8). However, in Iran, due to lack of large scale studies, no diagnostic reference levels had been set for X-ray diagnostic procedures. Because of the lack of this standards in Iran, in this study we hope to define some guidelines for technologists during panoramic imaging to make as low as possible dosage for patients and radiology perssonnels. In a comprehensive research project carried out by Asadinezhad M, Bahreyni Toossi MT in 2008 ,they proposed the first Iranian diagnostic reference levels(9),(10).ESD is amount of skin absorbed dose at the entrance point of the X-ray beam.ESD measurement can be performed directly or indirectly. Termo Luminecent Dosimeter (TLD)measures the ESD directly(11).

Provisions of the International Commission on Radiological Protection (ICRP)60emphasize the limit dose for the annual occupational exposure to50 milli sivret per year. However, this dose is more than the allowable amount of the general population (1 milli sievert per year). Occupational exposure of personnel should be controlled so that it does not exceed the following limits:

-The average annual effective dose is 20 millisievert (msv) for 5 consecutive years. (8),(12). Since the distribution of the absorbed radiation dose depends on the type of the panoramic device to determine skin dose head and neck regions. The main aim of this study was to assess the of skin absorbed dose of head and neck during panoramic radiographies. This study compare skin absorbed dose of head and neck in different age groups. As in Iran, there is lack of proper guidelines for radiographic exposures. This study help us to recognize that if decreasing the radiation dose during undergoing this imaging modality is needed. We hope this study will be a step to promote the radiation safety of patients who need $\mathrm{x}$ ray imaging modalities.

\section{Materials and Methods}

In this research project, 273 thermoluminescent dosimeters (TLD-100, Harshaw, USA) were used. The The lithiumfluoride chips ( $\mathrm{LiF}: \mathrm{Mg}$, Ti) were 3.3. $0.9 \mathrm{~mm}$ and the atomic number is nearly the atomic number of the soft tissue. The 90 samples were exposed under variable conditions $(\mathrm{kvp}=63$ to $77, \mathrm{ma}=4, \mathrm{~S}=12) .90$ patients who had referred to the Oral and Maxillofacial Radiology section of Babol school of dentistry for panoramic radiography attended in this study. We've split the samples into three age groups basis of needed setting conditions of imaging system(KVp and $\mathrm{S})$ :

1_Age group 4_10 years

2_Age group between 10 to 40 years

3 Age group of 40 years and above

Each chip was sealed in a plastic cover and had a special number. For each patient, 3 TLD numbers on the skin of the eye region (one centimeter away from external cantus of eye on contameatal line), parotid region (one centimeter away from tragus on alartragus line)and the thyroid gland region (on the thyroid cartilage skin in midline of neck) was carefully installed on skin with antiallergenic adhesive tape and numbers were selected randomly.3 TLD chips with fixed numbers were always used to determine background radiation. Three tanks were prepared for the TLDs: A storage tank for TLDs which do not receive radiation and another storage tank for TLDs which receive radiation, and a tank for keeping three background TLDs. Three tanks were always kept out of the x-ray room. For each age - sex group, there was a specially designed table in which exposure conditions and biographical information of patients was carefully recorded. After providing TLD panoramic radiographs, tlds were calibrated in dosimetry laboratory, National Radiation Protection Department to thermoluminescent signal was read out with a Harshaw 4500 (Harshaw, Bicron USA) reader. Then the data of each TLD number was recorded in the table. Since the aim was to measure the skin dose of organs, the exposure conditions (kvp, ma, S) of each age- sex group were not identical and exposure conditions in the system were set by radiology technologists based on their prior knowledge and experiences. Before starting the research project, no specific training or recommendations regarding the exposure conditions were performed for the radiology technologists to make exposure conditions be completely random .Mean \pm standard deviation was calculated with SPSS10 software. Data was analyzed by ANOVA statistic analysis .

\section{Results}

Findings on skin absorbed dose and skin equivalent dose for 90 samples and for three age groups of 4 _ 10 years, aged between 10-40 years, and above 40 years is as follows:

Mean \pm SD of skin absorbed dose for 90 samples is $0.47 \pm 0.09$ for head and neck region respectively (Table 1 ). The difference between average of skin absorbed dose in age _group 4_10ys and 10_40 ys and also between group age 1_40 ys and above 40 ys was significant.

Table1: skin absorbed dose of organs in each age group

\begin{tabular}{lllll}
\hline $\begin{array}{l}\text { Average of skin absorbed dose in age } \\
\text { group 4_10 years }\end{array}$ & $\begin{array}{l}\text { Average of skin absorbed dose in } \\
\text { age group(10_40 years) }\end{array}$ & $\begin{array}{l}\text { Average of skin absorbed dose in } \\
\text { age group above 40 years }\end{array}$ & $\begin{array}{l}\text {.Average of skin absorbed dose } \\
\text { for 90 patient }\end{array}$ \\
\hline $\begin{array}{l}\text { Organ } \\
\begin{array}{l}\text { Head and neck } \\
\text { SD } \pm \text { mean }\end{array}\end{array}$ & mGy & mGy & mGy & mGy \\
\hline
\end{tabular}


Table (2): exposure conditions.

\begin{tabular}{|c|c|c|c|c|c|c|c|c|}
\hline \multicolumn{3}{|c|}{$\begin{array}{l}\text { Average of exposure condition for age group } \\
4 \_10 \text { years }\end{array}$} & \multicolumn{3}{|c|}{$\begin{array}{l}\text { Average of exposure condition oor age } \\
\text { group 10_40 years }\end{array}$} & \multicolumn{3}{|c|}{$\begin{array}{l}\text { Average of exposure condition for age group } \\
\text { above } 40 \text { years }\end{array}$} \\
\hline \multicolumn{3}{|c|}{ Average age: 9.83 years. } & \multicolumn{3}{|c|}{ Average age:28.63years. } & \multicolumn{3}{|c|}{ Average age:52.63 years. } \\
\hline $\mathrm{S}$ & Ma & Kvp & $\mathrm{S}$ & $\mathrm{Ma}$ & Kvp & $\mathrm{S}$ & $\mathrm{Ma}$ & Kvp \\
\hline 17 & 10 & 65 & 18 & 10 & 69 & 19 & 9 & 68 \\
\hline
\end{tabular}

\section{Discussion}

In a study was performed by Gijbels $\mathrm{F}$ etal in 2005, absorbed dose and effective radiation dose were measured.

The result of the effective dose of radiation for the patients was calculated 8.1 micro sirvet (only for the parotid glands) by the use of panoramic machine-like the device used in the our research and the absorbed dose for the thyroid gland was calculated 52.2 micro gray (by the use of cranex Excel)(13). But in the results of our study, effective skin absorbed dose of the parotid gland, the effective dose of the parotid gland, and the skin absorbed dose of thyroid for 90 samples are 2.3, 2.3 and $130 \pm 80$ micro gray respectively. As it is obvious, there is a difference between effective dose of parotid gland and the findings of the present study. But overall reasons for the differences are due to:

1-Using phantom containing 100 TLD installed on various sections.

2- This test was performed only 10 times with five different devices.

3- Exposure conditions were identical in each experiment.

In Doyle P. Et al. Study in 2006 Dose width product (DWP) , the quantity recommended for assessment of patient dose for panoramic dental radiography,was determined by comparison of results obtained from 20 orthopantomographic units measured with three techniques :a small in-beam semiconductor detector and Xray film, a pencil ionization chamber and an array of thermo luminescent dosimeters (TLDs). The DWP for $30 \%$ of the units tested exceeded the diagnostic reference dose of $65 \mathrm{mGy} \mathrm{mm}$, recommended by the National Radiological Protection Board(14).

In a comprehensive research project carried out by Asadinezhad M, Bahreyni Toossi MT in 2008 ,they proposed the first Iranian diagnostic reference levels.

The following seven routine types (14 projections) of Xray examinations were studied: Antero-Posterior(AP) abdomen, AP cervical spine, Lateral (LAT)cervical spine, AP chest, LAT chest, Postero-Anterior(PA) chest, AP lumbar spine, LAT lumbar spine, AP pelvis, AP skull, LAT skull, PA skull, AP thoracicspine and LAT thoracic spine. Cases considered weret hose for which the images were diagnostically acceptable.Patient's entrance surface dose (ESD) was also measured by TLD chips.DRL determined for each imaging modality. The patient dose survey in Iran is still going on with expanding measurements for interventional radiographies, CT scan, mammography and angiography examinations (9),(10).

In an study was done by Garcia Silva MA et al.in 2008 effective dosages for Veraviewepocs dental panoramic images: analog film, digital, and panoramic scout for CBCT were measured by anthropomorphic phantom loaded with thermoluminescent dosimeters (TLD 100H) at 16 sites located in sensitive organs. The highest value (5.2 musv) was for Veraviewepocs Conventional. The Veraviewepocs Digital (2.7 musv) and Veraviewepocs 3D (2.95 musv) presented low effective doses in the same range.They conclude that the panoramic digital system delivered the least radiation dose. The use of the panoramic scout for cone-beam CT was marginally higher in dose than its 2D counterpart.(15),(16).

In a study conducted by Gavala $\mathrm{S}$ and his colleagues in 2009 to calculate the effective dose, test was repeated 6 times by the two types using conventional and digital panoramic devices, with the same exposure conditions on a phantom (equivalent to a 47 year old male), with TLD100(17).

Mean \pm SD absorption dose was calculated for conventional panoramic Planmeca promax $(\mathrm{ma}=6, \mathrm{kvp}=66$, $\mathrm{S}=16)$. The results were announced $(30 \pm 11) \mathrm{mgy},(315 \pm$ 42) mgy, and $(60 \pm 27)$ mgy for eyes , parotid gland and thyroid gland respectively. Results of effective dose were announced 3, 9 and $0.02 \mu \mathrm{sv}$ for thyroid gland, parotid gland and buccal skin respectively.

Reasons for the observed difference between the results of above study and the findings of the present study are as follows:

1 - Kind of panoramic machines

2 - The same exposure conditions for the six test with conventional and digital panoramic devices

3- Using a phantom instead of real patient.

4 - number and location of the TLD

5 - Tissue weighting factor was based on the ICPR60 study reported in 1990

In a related article published by Matsuo A. Et al in 2011 to assess the Absorbed dose and the effective dose of panoramic temporo mandibular joint. They measured the doses received by various organs and calculated the effective doses.they used an anthropomorphic phantom, loaded with thermoluminescent dosimeters (TLD), located at 160 sensitive sites. The dose shows the sum value of irradiation on both the right and left sides. In addition,they set a few different exposure field sizes.the result was: The 
effective dose for a frontal view in Panoramic TMJ was 11 $\mu \mathrm{sv}$ that for the lateral view was $14 \mu \mathrm{sv}$. They recommend that the size of the exposure field in Panoramic TMJ be decreased(18).

In a related rearch project performed by Grünheid $\mathrm{T}$ et al. In 2012 dose of a panoramic machine and a cone beam computed tomography device were measured by thermoluminescent dosimeters placed in 20 sites inside a head and neck phantom . Effective doses were calculated using the tissue-weighting factors recommended by the 2007 International Commission on Radiological Protection. The effective doses for digital panoramic was measured $21.5 \mu$ sv.they conclude that although CBCT is providing additional diagnostic and therapeutic benefits, also exposes patients to higher levels of radiation than conventional digital radiography(19).

It is not easy to measure exact radiation dose in studies. The problem arises from the fact that the radiation dose from a panoramic radiograph with a Well-Collimated $\mathrm{x}$ ray beam, is not fixed around the patient and has fluctuation. So the scattered radiation dose is dependent on patient anatomy and the imaging geometry geometry.

More information are available is the result of using 100 TLD on phantom, using different devices and has been obtained under same exposure condition. Therefore, compared with present study and findings, radiation spectrum has more uniform distribution. This is justify the differences between obtained results in this study and other studies.

This study is not a separate report of critical organ(such as parotid, thyroid gland ,etc.)skin absorbed dose such as the studies of above discussed them, this study shows the accumulative dose of head and neck during a panoramic radiography under different conditions in different age group .Table 1 indicates that the head and neck skin absorbed dose is greater in age group above 40 years and less in children below 10 years. The age group 10_40 years received intermediate amount of radiation exposure. With consideration to the table 2 and different exposure conditions for each age group (much for older age group),this may justify the amount of head and neck absorbed dose difference. However not only the age ,but also the other factors such as size is plays a critical role in determination of exposure condition, but because of the wide range of age that considered in intermediate age group ( 30 years in age group 10_30)the size and age is quite relative and estimation errors become less.

\section{Conclusions}

As there are major differences in the rate of organs absorption dose in panoramic radiography depending on the type, number and exact location of dosimeters, exposure conditions, annually calibration and the types of devices, and on the other hand (DRL) is still unknown on panoramic radiographs in $\operatorname{Iran}(6),(9),(10)$, there is no possibility to compare the results with DRL.Because of lack of distinct DRL in Iran, practical guidelines for reducing the exposure usage seem's to be usefull as a local recommendation.

Thus, in most countries, measuring the exact radiation dosage that a patient is receiving during radiological examinations is the main and inevitable program in related radiation safety centers(4). So every few years in some countries including Iran the dosage of radiation being received by patients is determined with statistical methods and dosimeters. So proper safety procedures and protection of patients can be applied according to the determined amount of radiation received by patients.

This study conclude that decrease of radiation dose seems to be achievable with lower exposure condition with this panoramic unit.

It can be obtain practically with decreasing the exposure conditions(in this machine:KVp and $\mathrm{S}$ ). In addition for the patients that have the size of a patients of younger age group,redused radiation dosage is needed.It is practically achived by radiology technologists with reducing the exposure conditions (for example:KVp and $\mathrm{S}$ ) to provide lower radiation dosage .Further study should be done to determine that how much decrease of radiation dose doesn't have significant effect on decreasing image quality

\section{References}

[1] Ribeiro DA. Cytogenetic biomonitoring in oral mucosa cells following dental X-ray. Dentomaxillofac Radiol. 2012 Mar;41(3):181-4.

[2] Batista WO, Navarro MV, Maia AF.Effective doses in panoramic images from conventional and CBCT equipment.Radiat Prot Dosimetry. 2012;151(1):67-75. Epub 2011 Dec 14.

[3] Williams JR, Montgomery A.Measurement of dose in panoramic dental radiology. $\mathrm{Br}$ J Radiol. 2000 Sep;73(873):1002-6.

[4] Zhang Y, Li X, Segars WP, Samei E. Organ doses, effective doses, and risk indices in adult CT: comparison of four types of reference phantoms across different examination protocols. Med Phys. 2012 Jun;39(6):3404-23.

[5] Ludlow JB. Comment on "Effective dose range for dental cone beam computed tomography scanners".Eur J Radiol. 2012 Dec;81(12):421920.

[6] S.M.J. Mortazavi , M. Ghiassi-Nejad, M. Bakhshi , M. Jafari-Zadeh , A. Kavousi , J. Ahmadi, et al. Entrance Surface Dose Measurement on the thyroid gland in orthopantomography: The need for optimization. Iranian Journal of Radiation Research. 2004; 2 (1) :21-26.

[7] [No authors listed]Radiological protection and safety in medicine. A report of the International Commission on Radiological Protection.Ann ICRP. 1996;26(2):1-47.

[8] [No authors listed]Diagnostic reference levels in medical imaging: review and additional advice. Ann ICRP. 2001;31(4):33-52 
[9] Asadinezhad M, Bahreyni Toossi MT. Doses to patients in some routine diagnostic X-ray examinations in Iran: proposed the first Iranian diagnostic reference levels. Radiat Prot Dosimetry. 2008;132(4):409-14. Doi: 10.1093/rpd/ncn308. Epub 2008 Dec 23.

[10] Toosi MT, Asadinezhad M. Radiat Prot Dosimetry. Local diagnostic reference levels for some common diagnostic Xray examinations in Tehran county of Iran.2007;124(2):13744. Epub 2007 May 10.

[11] Faghihi R, Mehdizadeh S, Sina S, Alizadeh FN, Zeinali B, Kamyab GR, Aghevlian S, Khorramdel H, Namazi I, Heirani M, Moshkriz M, MahaniH, SharifzadehM. Radiation dose to neonates undergoing $\mathrm{X}$ ray imaging in special care baby units in Iran.Radiat Prot Dosimetry. 2012 Jun;150(1):55-9. Doi: 10.1093/rpd/ncr373. Epub 2011 Nov 28.

[12] White SC, Pharoah MJ. Oral radiology: principles and interpretation. 6th ed. New Delhi : Mosby, $2009: 31.87$.

[13] Gijbels F, Jacobs R, Bogaerts R, Debaveye D, Verlinden $\mathrm{S}$, Sanderink G. Dosimetry of digital panoramic imaging. Part I: Patient exposure. Dentomaxillofac Radiol. 2005 May;34(3):145-9.

[14] Doyle P, Martin CJ, Robertson J.Techniques for measurement of dose width product in panoramic dental radiography.Br J Radiol. 2006 Feb;79(938):142-7.
[15] Garcia Silva MA, Wolf U, Heinicke F, Gründler K, Visser $\mathrm{H}$, Hirsch E. Effective dosages for recording Veraviewepocs dental panoramic images: analog film, digital, and panoramic scout for CBCT. Oral Surg Oral Med Oral Pathol Oral Radiol Endod. 2008 Oct;106(4):571-7. Epub 2008 Jul 7.

[16] Lorenzoni DC, Bolognese AM, Garib DG, Guedes FR, Sant'anna EF.Cone-beam computed tomography and radiographs in dentistry: aspects related to radiation dose. Int J Dent. 2012;2012:813768. Epub 2012 Apr 4.

[17] Gavala S, Donta C, Tsiklakis K, Boziari A, Kamenopoulou V, Stamatakis

HC.Radiation dose reduction in direct digital panoramic radiography. Eur J Radiol. 2009 Jul;71(1):42-8. doi: 10.1016/j.ejrad.2008.03.018. Epub 2008 May 2.

[18] [Article in Japanese]Matsuo A, Okano T, Gotoh K, Yokoi M, Hirukawa A, Okumura S, Koyama S. [Absorbed dose and

the effective dose of panoramic temporo mandibular joint ra diography]. Nihon Hoshasen Gijutsu Gakkai Zasshi. 2011;67(10):1275-83.

[19] Grünheid T, Kolbeck Schieck JR, Pliska BT, Ahmad M, Larson BE. Dosimetry of a cone-beam computed tomography machine compared with a digital x-ray machine in orthodontic imaging. Am J Orthod Dentofacial Orthop. 2012 Apr;141(4):436-43. 